\title{
Tarımsal Üretim Gerçekleştiren İşletmelerin Faaliyetlerinin Hedef Maliyet Yöntemine Göre Değerlendirilmesi
}

\author{
DOI: $10.26466 /$ opus. 563520
}

\author{
Eray Cetin ${ }^{*}$ - Nermin Bahşi ${ }^{* *}$ \\ * Öğr. Gör. Dr, Osmaniye Korkut Ata Üniversitesi, Düziçi MYO, Düziçi / Osmaniye / Türkiye, \\ E-Posta: eraycetin@osmaniye.edu.tr \\ ORCID: 0000-0001-8552-9584 \\ ** Dr. Öğr. Üyesi, Osmaniye Korkut Ata Üniversitesi, Kadirli Uyg.Bil. Y.O, Osmaniye / Türkiye \\ E-Posta: nerminbahsi@osmaniye.edu.tr ORCID:0000-0003-1630-7720 \\ Öz
}

Günümüzde üretim yapan işletmelerin göz önünde bulundurmak zorunda oldukları konular fiyat, maliyet ve kâr konularıdır. Çünkü, bugünün rekabet anlayışı çerçevesinde, fiyatlar artık işletmeler tarafindan değil, rekabetin yaşandığı pazarlar tarafından belirlenmektedir. Ortaya çıkan maliyetlerine göre belirli bir miktar kâr öngören ve buna göre fiyat belirleyen işletmeler yaşanan bu rekabette geride kalmaya ve kaybetmeye mahkumdurlar. Bu anlayış yerine piyasada belirlenen fiyatlara göre öngördükleri belirli bir miktar kâr ile maliyetlerini belirlemeleri ve bu maliyetleri temel alarak hareket etmeleri gerekmektedir. Müşteriler sadece fiyatı değil aynı zamanda beklentileriyle, üretilen ürünlerin kalitesini de belirlemektedirler. Bu çalışmanın amacı, tarımsal üretim faaliyetlerinde bulunan işletmelerde hedef maliyetleme anlayışının getireceği yararların irdelenmesidir. Hedef maliyetin gerçekleştirilebilmesi ve işletme faaliyetlerinin sürdürülebilirliğinin să̆lanması için işletmenin tüm bölümlerinin katıllmlarının sağlanması ve plânlamanın üretim öncesinde başlaması gerekmektedir. Konu tarımsal üretim gerçekleştiren işletmeler açısından değerlendirilecek olursa, tarımsal ürünlerin üretimi ve pazarlanmasında hedef maliyetleme anlayışının benimsenmesi, maliyet yönetimi anlayışının dışında üretim ve gelecek plânlaması açısından önem taşımaktadır.

Anahtar Kelimeler: Tarım, Tarımsal Üretim, Tarımsal Üretim Maliyetleri, Maliyet, Hedef Maliyetleme 


\title{
The Evaluation of the Activities of the Agricultural Production Enterprises According to the Target Cost Management
}

\begin{abstract}
The factors the production companies should take into account are price, cost and profit. Because pries are determined not by the companies themselves but the markets in competiton within the frame of today's competition approach. Therefore, the companies estimating a ratio pf profit and determinig price according to its costs are obliged to suffer from competition and fail. Instead of the approach above, companies should determine their costs by projecting an amont of profit according to the prices determined by the market and act with theses costs in mind. Customers determine not only the price but also the quality of goods and services with their expectations. The purpose of this study is to examine the advantages stemming from the target cost management approach in agricultural production companies. In order to manage target cost and sustain the activities of the company, participation of all parts of company and planning are of critical importance When the subject is evaluated in terms of agricultural production companies, applying the target cost management approach in production and marketing the agricultural products are important with regard to production and planning apart from cost management approach.
\end{abstract}

Keywords: Agriculture, Agricultural production, Cost, Agricultural production costs, Target cost management. 


\section{Giriş}

Dünyadaki tüm ülkelerde üretim hacimleri ve ürün çeşitliliği farklı olsa da tarımsal faaliyetler gerçekleştirilmekte ve tarımsal ürünler üretilmektedir. Diğer ülkelerde olduğu gibi ülkemizde de tarım sektöründe yaşanan en büyük sorunlardan bir tanesi tarımsal maliyetler ve hesaplanması konusudur. Tarımsal üretim maliyetleri konusuyla ilgili olarak ulusal ve uluslararası seviyede çeşitli çalışmalar bulunmaktadır. Örneğin; Jack ve Jones (2008) muhasebede brüt kâr marjı sisteminin kullanımının bir etkisi olarak, tarım iş plânlaması üzerinde maliyetlerin büyük bir kısmının sabit nitelikte olduğu ve kâr maksimizasyonunu en iyi şekilde elde etmenin yolunun faaliyet ölçeğini artırarak bu maliyetleri yaymak olduğunu vurgulamışlardır. Bayramoğlu vd. (2010) de aynı yaklaşımla tarımsal maliyetlerle ilgili olarak; tarımsal alanda faaliyet gösteren işletmelerin en önemli uğraşılarının maliyetleri düşürmek olduğunu ve bunun üretimin etkinliğinin artırılması suretiyle gerçekleşebileceğini belirtmişlerdir. Ancak üretim ölçeğinin genişletilmesi ve üretimin artırılması maliyetlerin etkin yönetilmesi için her zaman çözüm olmayabilir. Çünkü, her şeyden önce tarımsal faaliyetler dış koşullardan çok yüksek düzeyde etkilenmektedirler ve dış faktörlere bağlı olarak faaliyet riski de artış göstermektedir. Hatta üretim ölçeğinin artırılmasına bağlı olarak faaliyet zararının artışı bile söz konusu olabilmektedir. Bu açıdan bakıldığında maliyet yönetimi için daha etkin bir yönteme ihtiyaç duyulduğu öngörülebilir. Elde edilecek olan kazancın, satış kârının artırılmasından ziyade hedeflenen belli bir maliyet noktası kapsamında maliyetlerin azaltılması yoluyla hareket eden bir maliyet sistemi olan hedef maliyetleme sisteminde, öncelikle üretimle alakalı maliyetlerin üretim plânlaması aşamasında belirlenerek azaltılması gerekmektedir. Hedef maliyet yöntemi ileriye dönük faydalar sağlamaktadır.

Gagne ve Discenza (1995), piyasa odaklı yönetimi organizasyon genelinde uygulayabilmek için ölçüm ve maliyet kontrol sistemlerinin tasarlanması gerektiğini ve maliyet yönetim metotlarıyla, üretimde israfların ortadan kaldırılarak maliyet düşürme konusunda adım atmaları gerekliliğinden bahsetmişlerdir. Standart maliyetler ve geleneksel maliyetlendirme bu konularda yetersiz kalmakla birlikte hedef maliyet yaklaşımı 
maliyetlerin düşürülmesi konusunda etkin bir yöntem olarak nitelendirilmiştir. Everaert vd. (2006), hedef maliyeti; "Yeni ürün geliştirme sürecinde, ürün kârlılığını artırmak için, ürünlere yönelik olarak hedef maliyet belirleme ve işletmenin tüm birimlerinin belirlenen hedef maliyeti gerçekleştirmek için motive edilmesi suretiyle faaliyet gösterilmesi" şeklinde tanımlamışlardır. Gopalakrishnan vd. (2007), yapmış oldukları çalışmalarında üretim faaliyetlerindeki verimliliğin, maliyetleri etkin hale getirmek suretiyle artırılabileceğini ve bu amaca ulaşabilmek için hedef maliyetin etkin bir yöntem olduğunu vurgulamışlardır.

Ancak, maliyetlerin aşağ 1 çekilmesi, üretilecek olan ürünlerin kalitesizleştirilmeleri anlamını taşımamalıdır. Çünkü, piyasada müşteriler tarafından belirlenen fiyat dışında aynı zamanda müşteri beklentileri dahilinde bulunan kalite düzeyi de talebin en belirleyici unsurları arasındadır. Tarımsal üretim yapan işletmeler açısından kalite önemli bir kavramdır. Çünkü, tarımsal ürünler kullanım alışkanlığı, fiyat, ihtiyaçların giderilmesi dışında doğrudan insan sağlığı ile alakalı bir konudur. Sağlık söz konusu olunca müşterilerin talepleri de bu doğrultuda değişiklik göstermektedir. Müşteriler tarımsal ürünleri tercih ederken fayda-fiyat analizinin d1şında aynı zamanda ürünlerin sağlık koşullarını da göz önünde bulundurmaktadırlar. Tarım ürünlerinde kalite her şeyden önce sağlık kriterlerine bağlıdır. Dolayısıyla, tarımsal üretim yapan işletmeler maliyetlerin azaltılması dahilinde ürünlerin kalitesini ve sağlık koşullarını da göz ardı etmemelidir. Hedef maliyet kapsamında sadece ürünlerle ilgili üretim giderlerinin düşürülmesi değil, aynı zamanda tedarik sürecinde elde edilecek olan girdilerle ilgili olarak plânlama çalışmalarının yapılması gerekmektedir.

Hlouskova vd. (2018), çalışmalarında tarımdaki iş gelişiminin ekonomik sürdürülebilirliği dikkate alınması suretiyle gerçekleştirilebileceğini belirttikleri çalışmalarında, tarımın ekonomik sürdürülebilirliğinin değerlendirilmesi için üretim sonuçlarının önem taşıdığına değinmişlerdir. Üretim sonuçlarını ortaya çıkaran unsurlar ise maliyetler (giderler) ve gelirlerdir. Tarımsal üretimde benimsenecek olan hedef maliyet yaklaş1miyla üretim maliyetlerinin aşağı çekilerek elde edilecek olan faaliyet kârının artırılması öngörülmektedir.

Aslında, hedef maliyet sistemi maliyetlerin kontrol edildiği basit bir araçtan daha çok üretimin plânlaması aşamasından, üretim faaliyetlerinin 
gerçekleştirildiği noktaya kadar birçok konuda etkin bir fonksiyonu olan bir enstrümandır. Sürdürülebilir tarım için maliyetlerin kontrol altına alınması gerekmektedir. Bu nedenle, hedef maliyet sistemi iyi bir maliyet yönetimi tercihi olacaktır.

\section{Maliyet Kavramı}

Maliyet kavramı, işletmeler açısından büyük öneme sahip olmakla birlikte, işletme faaliyetlerinin sürdürülebilirliği açısından hayati bir konumdadır ve aynı zamanda işletme biliminde çok kullanılan bir terimdir. Buna rağmen, maliyeti tüm yönleriyle kapsayan bir tanım yapılamamaktadır. Ancak genel olarak maliyet; "Belirli bir amaca ulaşmak için katlanılan fedakârlıkların parasal tutarı" olarak tanımlanmaktadır (Küçüksavaş, 2006; Erol, 2008; Savc1, 2008; Kaygusuz ve Dokur, 2012; Abdioğlu, 2012). Kavramsal olarak maliyet tek başına bir anlam ifade etmemekle birlikte, maliyeti hesaplanmak istenilen birimlere ise maliyet objeleri adı verilmektedir. Maliyet objelerine örnek olarak; mal veya hizmet maliyeti, faaliyet veya iş maliyeti, proje maliyeti, kısım maliyeti, program maliyeti verilebilir (Küçüksavaş, 2006).

Üretim Maliyetleri: Bir mal veya hizmetin elde edildiği üretim işletmeleri açısından maliyet ise belirli bir mamulü üretmek ve müşteriye teslim etmek için katlanılan fedakârlıkların parasal karşılığıdır (Kaygusuz ve Dokur, 2012). Üretim işletmelerindeki amaç, mamul üretimini gerçekleştirmektir. Bunun için, üretim faktörleri bir araya getirilerek üretim faaliyetlerine yönlendirilirler. Üretim maliyetleri; direkt ilk madde ve malzeme, direkt işçilik ve genel üretim maliyetlerinin bileşiminden oluşmaktadır ve üretim maliyetlerinin tespit edilmesi, işletmeler açısından hayati önem taşımaktadır.

İşletmenin üretmiş olduğu ürünlerin fiyatlarının tespit edilebilmesi ancak, maliyetlerinin tespitine bağlı olarak gerçekleştirilebilmektedir. Bunun dışında, gider ve maliyet kontrolünün yapılabilmesi ve üretimle ilgili alınacak olan kararlar açısından da maliyetlerin tespit edilmesi zorunludur. Bunun dışında, üretim plânlaması ve stok maliyetlerinin tespit edilebilmesi açısından da üretim maliyeti bilgisine ihtiyaç duyulmaktadır 
(Erol, 2008). Üretim maliyetleri, üretim şartlarına göre dönüşüm maliyetleri olarak da adlandırılabilir, çünkü üretim maliyetlerinin önemli bir bölümü dönüşüm ve işlem maliyetlerini içermektedir. Dönüşüm maliyetleri, hammaddenin fiziksel değişim sürecine eşlik eden maliyetlerdir ve belirli bir değere sahip olan bir ürünün elde edilmesine neden olmaktadır (Sharapa, 2016).

Tarımsal Üretim Maliyetleri: Tarım işletmeleri de diğer üretim işletmelerinde olduğu gibi üretim faktörlerinin bir araya getirilerek, çıtı elde edilmesi esasına dayanan bir çerçevede faaliyetlerini sürdürürler. Girdi, üretim faaliyetleri ve çıktı döngüsünü göz önünde bulunduracak olursak bu işletmeler de üretim maliyetlerine katlanmak zorundadırlar. Tarımsal faaliyetlerin ekonomik olarak sürdürülebilirliğinin sağlanması için, üretim sonuçlarının göz önünde bulundurulması gerekmektedir. Üretim sonucuna göre, sürdürülebilir tarımsal faaliyetlerin gelir ve gider karşılaştırılmasında maliyetler önemli bir konum teşkil etmektedir.

Tarımsal faaliyette bulunan işletmelerin performans değerlemesine yönelik çeşitli yaklaşımlar bulunmaktadır. Bunlardan bir tanesi; çok faktörlü verimlilik oranı olup, tarımsal çıktıların tarımsal girdilere oranlanmasıdır. Avrupa Komisyonu, Tarımsal Muhasebe Veri Ağı'nda (FADN/ Farm Accountancy Data Network) yer alan bir diğer yöntem ise farklı amaçlara yönelik olarak ortaya konulan Çiftlik Net Katma Değeri veya Çiftlik Net Geliri göstergelerini kullanarak ifade edilen gelirdir ve bu noktada üretim maliyetleri çeşitli bakış açılarına göre sıralanabilmekle birlikte, toplam maliyetler esasen özel maliyetler, tarımsal giderler, dış maliyetler ve diğer maliyetler olmak üzere sınıflandırılmaktadır. Maliyetlere ilişkin sıralama Tablo-1'de yer almaktadır (Hlouskova vd., 2018):

Tarımsal üretim maliyetlerinin belirlenmesinde ortaya konulan başka bir yaklaşımda ise, tarım işletmelerinde maliyeti oluşturan unsurlar, tarımsal maliyeti oluşturan giderler olarak adlandırılmakta ve esas olarak beş gruba ayrılmaktadır (Adıyaman ve Günay, 2008):

- Arazi kirasi

- İşçilik giderleri

- Cari giderler

- Amortismanlar

- Faiz. 
Tablo 1. Tarımsal Maliyet Stralama Düzeni

\begin{tabular}{llll}
\hline TOPLAM MALIYETLER & & \\
\hline Özel Maliyetler & Genel Üretim Giderleri & Diş Maliyetler & Diğer Maliyetler \\
\hline Gübre & Enerji & Ücretler & Amortismanlar \\
\hline Tohum & Sözleşme Maliyetleri & Faiz Ödemeleri & Vergiler \\
\hline Bitki Koruma & $\begin{array}{l}\text { Bina ve Makine Bakım } \\
\text { Maliyet. }\end{array}$ & Kiralar & \\
\hline Besleme & Diğer Doğrudan Girdi Maliyet. & \\
\hline Veterinerlik Gid. & & \\
\hline Diğer, Bitkisel ve Hayvansal Gid. & \\
\hline (Kaynak: Hlouskova, Zeniskova ve Prasilova, 2018) &
\end{tabular}

Ayrıca sabit giderler dışında, üretim hacmine bağlı olarak gerçekleşen değişken giderler bulunmaktadır. Bitkisel üretimde tohum, fidan, ilaç, gübre, sulama, yakıt, bakım-onarım, geçici işçilik, ürün satış-depolamataşıma, sigorta gibi giderler değişken nitelikte olup üretilen ürün hacmine bağlı olarak giderlerin seviyesi de değişmektedir. Hayvansal üretimde de aynı şekilde değişken giderler söz konusudur; yem, veterinerlik, çeşitli enerji, geçici iş̧̧ilik, taşıma ve çeşitli bakım gibi konularda gerçekleşen giderler söz konusudur.

Faaliyetlerin sürekliliğinin sağlanmasında temel olan unsur, işletmenin kâr elde etmesi ve bu kârın sürdürülebilir nitelikte olması gerekmektedir. Sürdürülebilir kâr açısından önemli olan temel unsur ise, maliyetler olmaktadır. İşletme biliminde, bir mal veya hizmetin elde ediliş maliyetini hesaplayabilmek için en basit yöntem, üretimde kullanılan girdilerin, diğer bir ifadeyle, üretim faktörlerinin parasal karşıllılarının toplanmasıdır. Ancak, iktisat biliminde, üretim maliyetlerinin gerçek değerlerinin hesaplanabilmesi için fırsat maliyeti olarak adlandırılan üretim faktörlerinin vazgeçme maliyetlerinin de göz önünde bulundurulması gerekmektedir.

Buna göre tüm girdilerin maliyetleri; açık maliyetler ve örtük maliyetler olarak nitelendirilmekte ve üretim maliyetleri ikisinin toplamindan oluşmaktadır. Açık maliyetler; üretimi gerçekleştiren işletmenin sahibi olmayanlara, üretime katkıları karşıllğında fiilen yapılan ödemeleri kapsamaktayken, örtük maliyetler; üretimi gerçekleştiren işletme tarafından o işletmenin sahiplerine üretime katkıları karşılığında yapılması gereken ödemeleri kapsamaktadır, örtük maliyetler kısaca, sermayenin kiralanma 
maliyetidir (Yaşar, 2011). Açık maliyetlere, işçi ücret ve ödemeleri, hammadde, yardımcı malzeme maliyetleri örnek olarak verilebilirken, örtük maliyetlere işletmenin sahip olduğu makine, araç-gereç ve teçhizatların kiraya verilmeleri halinde elde edilecek olan kira geliri tutarı verilebilir.

\section{Hedef Maliyet Yaklaşımı}

Tarım işletmeleri açısından hedef maliyet yaklaşımı çok farklı bir plânlama ve ekonomik ortam oluşturmakla birlikte, aslında tarım dışı üretim sektörlerinde uygulanan ve başarı sağlanan bir maliyet yönetimi yaklaşımıdır. Esasen, kârlılık her zaman daha fazla ürün, daha fazla ekim alanı veya daha fazla hayvansal ürün elde edilmesi anlamını taşımamakla birlikte, optimum maliyet temeline dayanmaktadır. Hedef maliyet yönetimi esasen iki temele dayanmaktadır. İlk olarak, rasyonel bir şekilde hedef maliyetin belirlenmesi ve sonrasında oluşturulacak süreçler aracıl1ğıla hedeflenen maliyete ve buna bağlı olarak arzu edilen kâr seviyesine ulaşılmasıdır.

Hedef maliyet yaklaşımı, maliyet yönetim metotları içerisinde yer almaktadır. Üretilecek olan bir ürünün hedef maliyetinin belirlenmesinde ilk adım, ürünün satış fiyatını ve işletmenin öngördüğü kâr marjını belirlemektir. Üretim maliyetinin belirlenmesinde istenilen kâr, satış fiyatından çıkarılmaktadır ve bunun sonrasında hedef maliyet, bileşenlerine ayrıştırılmaktadır. Hedef maliyetin aşılmaması gerekmekle birlikte fiili maliyetler hedef maliyeti aşarsa, üretim maliyetlerini düşürmek için çeşitli eylemler gerçekleştirilmelidir. Bu noktada üretim süreci yeniden yapılandirılabilir (Gopalakrishnan vd., 2007).

Hedef maliyet, veri ve bilgileri, ürünün hedef maliyetini belirlemek ve elde etmek için mantıksal bir dizin halinde kullanan disiplinli bir süreçtir. Dış değişkenler arasındaki dengeyi sağlamak ve ürünün belirlenen maliyet düzeyinde üretilmesi hedef maliyet yönetiminin görevidir. Ürünlerin satış fiyatları, müşterilerin, tedarikçilerin, satılma döneminin ve genel ekonomik koşulların önemli bir rol oynadığı piyasada belirlenmektedir. İşletme tarafından istenilen kâr, işletme sahip veya ortaklarının beklentilerine ve piyasa koşullarına göre değişiklik gösterdiği için, kontrol edilemeyen bir başka diş değiş̧kendir (Patrau ve Coca, 2017). Hedef maliyetleme yönetimi çeşitli aşamalardan oluşmaktadır. İlk aşama ve en önemlisi 
ürün için bir hedef kâr oluşturma aşamasıdır. Şekil-1'de hedef maliyet sürecinin genel bir özeti gösterilmektedir (Gagne ve Discenza, 1995):

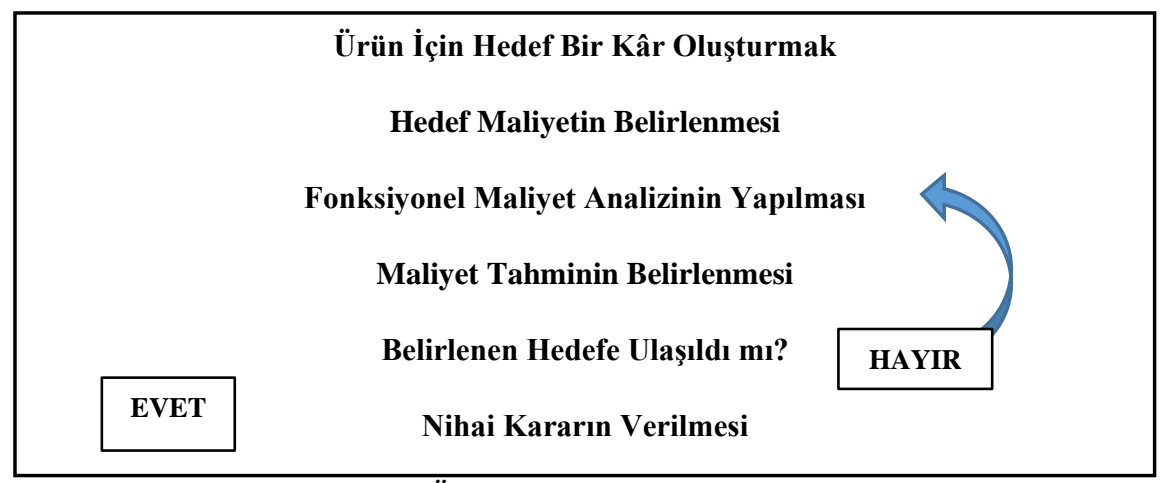

Şekil 1: Hedef Maliyet Süreci Özeti Kaynak: (Gagne ve Discenza, 1995)

\section{Tarımsal Üretim Yapan İşletmelerde Hedef Maliyet Yaklaşımı}

Tarım işletmelerinin performanslarının maliyetlendirilmesine yönelik temel metodoloji, 1950'lerden itibaren brüt kâr marjını ortaya koymak için doğrudan maliyetlerin tahsis edilmesi ve diğer tüm maliyetlerin sabit olarak değerlendirilmesi yöntemidir. Brüt kâr marjı sisteminin kullanılmasının kısmi bir sonucu olarak iş plânlaması geçmişte, maliyetlerin çoğunun sabit olmasına bağlı olarak maliyetleri düşürmenin ve kârın arttırılmasının en iyi yolunun faaliyet ölçeğini artırarak sabit maliyetlerin yayılması görüşü genel kabul görmüştür (Jack ve Jones, 2008). Maliyet uygulamalarının ve değerlendirmelerinin bu şekilde yürütülmesi maliyetlerin derecesi ile alakalı olmayıp işletmenin özellikle uzun vadeli maliyet oluşumlarının bir göstergesi olmamaktadır. Konu bu açıdan ele alındığında, tarımsal maliyetlerin yönetiminde, işletme performansı ve verimliliği üzerinde daha etkin olan farklı bir yaklaşıma ihtiyaç olduğu söylenebilir.

Piyasa koşulları göz önünde bulundurularak belirlenen hedef kâr sonrasinda hedef maliyet belirlenmektedir. Bu noktadan hareketle, fonksiyonel maliyet analizi yapılır. Fonksiyonel analizde üretimle ilgili olarak hedef maliyet ve fiili maliyetler karşılaştırılarak, alternatifler ortaya konulmaktadır. Alternatif maliyetlerin belirlenmesinde ise madde ve malzeme 
maliyetleri, gübre maliyetleri, sulama maliyetleri, alet ve makine maliyetleri, araç maliyetleri, ilaçlama maliyetleri, farklı üretim teknikleri ve diğer unsurların maliyetleri dikkate alınarak maliyet tahmini belirlenir. Belirlenen maliyet hedefine ulaşılması durumunda ise nihai karar verilerek üretime geçilir. Bunun yanında, sanayi üretiminden farklı olarak tarımsal üretimde faaliyetler birçok diş faktörden etkilenmektedir. Özellikle, iklim, sulama olanakları, hava koşullarındaki ani değişimler, hastalıklar, zararlılar gibi unsurlar ayn zamanda tarımsal üretim düzeyinde etkili olmaktadır. Bu bağlamda sadece girdi fiyatları faktörü değil, üretimi etkileyen diğer faktörler de tarımsal maliyetlerde önemli bir rol oynamaktadır.

Hedef maliyet kavramı, bir ürünün değerine katkıda bulunmayan, katma değeri olmayan ve üretimle ilgili alakasız faaliyetleri azaltmak için üretim aşamasında uygulanan yalın kavramlarla aynı temelde bulunmaktadır. Kalite, az sayıda tedarikçi kullanımı ve israfların azaltılması hedef maliyet yönetiminin önemli bir bileşeni olan, sürekli iyileştirme yaşam döngüsünün bir parçasıdır (Helms vd., 2005). Üretim sırasında meydana gelen, değer yaratmayan ve israf olarak nitelendirilebilecek her türlü işgücü ve malzeme kullanımının sonlandırılması neticesinde üretim maliyetleri azalmaktadır. Hedef maliyet belirlenirken, üretim sürecinin her safhası gözden geçirilmeli ve oluşabilecek israflar önceden tespit edilerek elimine edilmelidir.

Diğer taraftan, hedef maliyet sadece maliyetlerin azaltılması konusuna odaklanan bir anlayış olmamakla birlikte, aynı zamanda işletmenin amaçlarına ulaşmak için özellikle operasyonel süreçlerin rasyonalize edilmesi ve yeniden düşünülerek gerektiğinde faaliyetlerin yeniden plânlanmasını kapsayan metodolojik bir uygulamadır (Jack ve Jones, 2008). Hedef maliyet yaklaşımı ile maliyet analizlerinin gerçekleştirilmesi ve oluşacak fiyat dalgalanmalarına karşı üretim süreçlerinin yeniden yapılandırılarak uygulamaya konulması gibi çözümler mümkün olabilmektedir. Kalite anlayışı ile birlikte hareket edildiğinde hem iş süreçleri hem de üretim faaliyetleri sonucunda elde edilecek olan ürün kalitesi, ilgi görecek düzeye çekildiğinde, işletme verimliliği de artırılmış olacaktır. 


\section{Sonuç}

Tarımsal üretimde girdi maliyetleri ve üretim için gerçekleştirilen giderler, kârlılık ve faaliyetlerin sürdürülebilirliği açısından büyük önem taş1maktadır. Bu nedenle maliyetlerin kontrol altına alınarak, yönetilebilir hale getirilmesi gerekmektedir. Özellikle, maliyet kontrolü konusunda etkin bir yönetim aracı olan hedef maliyet yöntemi, tarımsal faaliyet gerçekleştiren işletmeler açısından da önem taşımaktadır. Bu çalışmada tarımsal faaliyet gerçekleştiren işletmelerin geleneksel maliyet yönetimi yöntemlerinin dışında hedef maliyet yönetimini benimsemeleri sonucunda oluşabilecek faydaların değerlendirilmesi amaçlanmıştır. Buna bağlı olarak, tarımsal üretim maliyetleri, hedef maliyet yönetimi kapsamında değerlendirilmiştir.

Hedef maliyet yönteminin uygulanabilmesi için işletme açısından hedef bir kâr düzeyi belirlenmesi ve buna bağlı olarak da hedef maliyetin ortaya konulması gerekmektedir. Bunun için öncelikle üretim girdilerinin plânlanması ve sonrasında işgücü plânlaması yapılması gerekmektedir. İşgücü istihdamı gerçekleştirilirken uzmanlık gerektirecek konularda nitelikli personel istihdam edilmeli, popülist personel politikalarından kaçınılmalıdır. Aynı zamanda işgücü ekonomisi sağlanabilmesi için tarımsal üretim işletmesinin uygulama alanları plânlanmalı ve gereksiz işgücü hareketlerinden kaçınılmalıdır. Bunun için öncelikle bir çiftlik avlusu belirlenmeli ve tarımsal üretim işletmesine ait bina ve türevleri efektif olarak bu avlu çerçevesinde dizayn edilmelidir. İyi bir satış ve dağıtım plânlanması da stoklanabilir ürünlerin gereksiz olarak stoklanmasının önüne geçecektir. Buna bağlı olarak hem depolama hem de işgücü giderlerinden tasarruf sağlanabilir. Hedef maliyet yaklaşımının diğer bir önemli unsuru da pazar payının ve satış hacimlerinin doğru olarak tahmin edilmesi ve buna göre üretimin plânlanması ve gerçekleştirilmesidir. Satış hacminin doğru tahmin edilmesi, gereksiz üretim faaliyetlerinin önüne geçilmesini sağlayacak ve gereksiz üretime bağlı olarak ortaya çıkacak olan fazla maliyetlerden kaçınılmış olacaktır. Bunun için öncelikle müşteriler ne ister, ne zaman ister ne kadar ister gibi soruların cevaplandırılması için iyi bir pazar araştırması yapılması gerekmektedir. Bu araştırmaya bağlı olarak plânlanacak olan üretim miktarları göz önünde bulundurularak üretim gerçekleştirilmeli ve hedeflenen maliyet düzeyi yakalanmalıdır. Tüm bu 
hususlar düşünüldüğ̈̈nde, işletmelerin gerçekleştireceği plânlama faaliyetlerinin ilk sırasında hedef kâr kavramı yer almalıdır. Ayrıca tarımsal ürünlere ilişkin pazar koşullarının değişkenliği de düşünülecek olursa, bu koşulların getireceği farklı talep düzeylerine göre üretimin gerçekleştirilmesi gerekir. Tarımsal üretim sadece girdi, üretim faaliyetleri, çıtı faaliyet döngüsü içerisinde ele alınmamalıdır. Çünkü, tarımsal faaliyetler, küresel ısınma, çevre, çevre kirliliği, iklim gibi üretim dışı koşullardan yüksek düzeyde etkilenen bir üretim şeklidir. Bütün bu dış koşulların, tarımsal faaliyet yapılacak bölgedeki uzun süreli ortalamaları hesaba katılarak tarım işletmesinin faaliyetleri plânlanmalıdır. Diğer üretim işletmelerinde olduğu gibi tarımsal üretim yapan işletmeler çoğunlukla, tarımsal ürüne ilişkin tasarım işlemlerini göz önünde bulundurmak zorunda değildir. Ancak hem üretim hem pazarlama faaliyetleri dahilinde faaliyet gösteren tarımsal işletmeler ürün pazarlaması konusunda, ürünlerin pazara sunumuna ilişkin yeni ve farklı uygulamalar geliştirebilirler. Bu uygulamaların üretimden önce plânlama aşamasında gerçekleştirilmesi gerekmektedir.

Günümüzde birçok ülkenin yüksek tarımsal maliyetler nedeniyle tarım ürünü ithal ettiğini görmekteyiz. Gelişmiş tarım ülkelerinde ise yapılan teknoloji ve sermaye yatırımları aracılığıyla tarımsal üretim maliyetlerinin düşürüldügü ve tarımsal gelirin artırılarak aynı zamanda, milli gelirde artış sağlandığı görülmektedir. Bu noktadan hareketle, maliyetlerin düşürülerek, tarımsal gelirin ve bbuna bağlı olarak tasarrufların artırılması ve nihayetinde tarımsal yatırımlara dönüştürülebilmesi için maliyetlerin gözlemlenerek kontrol altına alınmasına ihtiyaç bulunmaktadır. Hedef maliyet yaklaşımı belirtilen hususların gerçekleştirilmesinde etkin bir maliyet yönetim aracı olarak görülmektedir. 


\title{
EXTENDED ABSTRACT
}

\section{The Evaluation of the Activities of the Agricultural Production Enterprises According to the Target Cost Management}

\author{
Eray Çetin - Nermin Bahşi \\ Osmaniye Korkut Ata University
}

The factors the production companies should take into account are price, cost and profit. Because pries are determined not by the companies themselves but the markets in competiton within the frame of today's competition approach. Therefore, the companies estimating a ratio pf profit and determinig price according to its costs are obliged to suffer from competition and fail. Instead of the approach above, companies should determine their costs by projecting an amont of profit according to the prices determined by the market and act with theses costs in mind.

Customers determine not only the price but also the quality of goods and services with their expectations. The purpose of this study is to examine the advantages stemming from the target cost management approach in agricultural production companies. In order to manage target cost and sustain the activities of the company, participation of all parts of company and planning are of critical importance When the subject is evaluated in terms of agricultural production companies, applying the target cost management approach in production and marketing the agricultural products are important with regard to production and planning apart from cost management approach. In fact, the target cost system is an instrument that has an effective function in many aspects, from the planning stage of production to the point at which production activities are carried out, rather than a simple tool for controlling costs. For sustainable agriculture, costs need to be controlled. Therefore, the target cost system will be a good cost management choice.

Although the target cost approach creates a very different planning and economic environment for agricultural enterprises, it is actually a cost management approach that is applied and achieved in non-agricultural production sectors. The basic methodology for costing the performance of agricultural holdings is the method of allocating direct costs and establishing a constant assessment of all other costs to establish the gross profit margin from the 1950s 
onwards. With the target cost approach, it is possible to carry out cost analyzes and to reorganize production processes against price fluctuations. When the product quality, which will be obtained as a result of both business processes and production activities, is taken to the level of interest when operating with the understanding of quality, operational efficiency will be increased. Input costs in agricultural production and production expenses are of great importance in terms of profitability and sustainability of operations. Therefore, costs should be controlled and made manageable.

Particularly, the target cost method, which is an effective management tool in cost control, is also important for enterprises performing agricultural activities. In this study, it is aimed to evaluate the benefits that may occur as a result of adopting target cost management in addition to traditional cost management methods. Accordingly, agricultural production costs have been evaluated within the scope of target cost management.

In order to apply the target cost method, a target profit level should be determined for the enterprise and accordingly the target cost should be put forward. For this, first of all, production inputs should be planned and then labor planning should be made. Qualified personnel should be employed in areas that require expertise while the labor force is being employed and populist personnel policies should be avoided. At the same time, the fields of application of agricultural production enterprise should be planned and unnecessary labor movements should be avoided in order to provide labor economy. For this, a farm yard should be determined first and the buildings and derivatives belonging to the agricultural production enterprise should be designed effectively within the framework of this yard. Good sales and distribution planning will also prevent unnecessary stocking of stockable products.

Agricultural production should not be considered only in the input, production activities, output activity cycle. Because agricultural activities are highly affected by non-production conditions such as global warming, environment, environmental pollution and climate. Taking into account the longterm averages of all these external conditions in the region where the agricultural activity will be carried out, the activities of the agricultural enterprise should be planned. As with other production enterprises, agricultural production enterprises often do not have to take into account the design procedures for agricultural products. However, agricultural enterprises operating in both production and marketing activities may develop new and different applications in terms of product marketing and the introduction of products 
to the market. These applications should be carried out at the planning stage before production.

Today we see that many countries import agricultural products due to high agricultural costs. In developed agricultural countries, it is seen that agricultural production costs are reduced by means of technology and capital investments and agricultural income is increased and at the same time national income increases. From this point of view, there is a need to monitor and control costs in order to reduce costs, increase agricultural income and consequently increase savings and ultimately convert them into agricultural investments. The target cost approach is seen as an effective cost management tool in realizing the mentioned issues.

\section{Kaynakça / References}

Abdioğlu, H. (2012). Maliyet Muhasebesi. Bursa: Dora Kitabevi.

Adıyaman, A., ve Günay, S. (2008). Türkiye'de yüksek tarım maliyeti sorununun çözümünde biyodizelin yeri/the importance of biodiesel for a solving of high agriculture cost problem in Turkey. Doğu Coğrafya Dergisi, 13(19), 105-122.

Bayramoğlu, Z., Aktürk, D. ve Tatlıdil, F.F. (2010). Kaynakların rasyonel kullanımının üretim maliyetleri üzerine etkisi: Kanola yetiştiriciliği örneği. Selçuk Üniversitesi Selçuk Tarım ve Gıda Bilimleri Dergisi, 24(3), 6268.

Erol, M. (2008). Maliyet muhasebesi. Ankara: Orion Kitabevi,.

Everaert, P, Loosveld, S., Acker, T.V., Schollier, M. ve Sarens, G. (2006). Characteristics of target costing: Theoretical and field study perspectives. Qualitative Research in Accounting \& Management, 3(3), 236-263.

Gagne, M.L. ve Discenza, R. (1995). Target costing. Journal of Business $\mathcal{E}$ Industrial Marketing, 10(1), 16-22.

Gopalakrishnan, B., Kokatnur, A. ve Gupta, D.P. (2007). Design and development of a target-costing system for turning operation. Journal of Manufacturing Technology Management, 18(2), 217-238.

Helms, M.M., Ettkin, L.P., Baxter, J.T. ve Gordon M.W. (2005). Managerial implications of target costing. Competitiveness Review: An International Business Journal, 15(1), 49-56.

Hlouskova, Z., Zeniskova, P. ve Prasilova, M. (2018). Comparison of agricultural costs prediction approaches. Agris on-line Papers in Economics and Informatics, $X(1), 1-13$. 
Jack, L. ve Jones, J.V.H. (2008). Facing up the new realities: The case for using relevant cost and target cost approaches in agriculture. Journal of Applied Accounting Research, 8(3), 116-145.

Kaygusuz, S.Y., ve Dokur, Ş. (2012). Yönetim muhasebesi. Bursa:Dora Kitabevi.

Küçüksavaş, N. (2006). Yönetim açısından maliyet muhasebesi. İstanbul:Kare Yayınları.

Patrau, D.D. ve Coca, C.E. (2017). Methodological considerations on the process of determining the target cost. Economics, Management and Financial Markets, 12(2), 122-130.

Savc1, M. (2008). Maliyet muhasebesine giriş. Trabzon:Murat-Han Yayınevi.

Sharapa, O. (2016). Methodological approaches to determining the level of transaction costs of sales of agricultural enterprises. Quantitative Methods in Accounting and Finance, 434, 174-180.

Yaşar, A. (2011). Bağımsız dış denetim kalitesinin kâr yönetimi üzerine etkisi: IMKB'de kayıtlı işletmeler üzerine bir uygulama. Doktora tezi, Çukurova Üniversitesi, Adana.

\section{Kaynakça Bilgisi / Citation Information}

Çetin, E. ve Bahşi, N. (2019). Tarımsal üretim gerçekleştiren işletmelerin faaliyetlerinin hedef maliyet yöntemine göre değerlendirilmesi OPUS-Uluslararası Toplum Araştırmaları Dergisi, 13(19), 2365-2380. DOI: 10.26466/opus.563520 